\title{
Study on the Influence of Sand Production on Seepage Capacity in Natural Gas Hydrate Reservoirs
}

\author{
Yongmao Hao $\mathbb{D}^{1,2}$ Jikai Liang, ${ }^{1,2}$ Chuixian Kong, ${ }^{3}$ Mingwu Fan, ${ }^{4}$ Hongzhi Xu, ${ }^{4}$ Fan Yang, ${ }^{1,2}$ \\ and Shiwei Yang ${ }^{1,2}$ \\ ${ }^{1}$ Key Laboratory of Unconventional Oil \& Gas Development (China University of Petroleum (East China)), Ministry of Education, \\ Qingdao 266580, China \\ ${ }^{2}$ School of Petroleum Engineering, China University of Petroleum (East China), Qingdao 266580, China \\ ${ }^{3}$ Research Institute of Exploration and Development, Xinjiang Oilfield Company, PetroChina, Karamay, Xinjiang 834000, China \\ ${ }^{4}$ CNPC Offshore Engineering Company Limited, Beijing 100028, China
}

Correspondence should be addressed to Yongmao Hao; haoyongmao@163.com

Received 16 November 2020; Revised 28 February 2021; Accepted 8 April 2021; Published 21 April 2021

Academic Editor: Guanglong Sheng

Copyright (C) 2021 Yongmao Hao et al. This is an open access article distributed under the Creative Commons Attribution License, which permits unrestricted use, distribution, and reproduction in any medium, provided the original work is properly cited.

Sand production has become a common phenomenon in the exploitation of unconsolidated natural gas hydrate reservoirs, which will hinder the long-term production of natural gas hydrate reservoirs. However, there are few literatures reported on the influences in reservoir physical properties such as permeability and porosity, and production laws caused by sand production. This paper provides a numerical model, coupled with reservoir sand-gas-water multiphase flow processes, which is capable to simulate the process of sand production in natural gas hydrate reservoirs. The simulation results indicate that sand settlement is mainly concentrated near the wellbore due to the high concentration of migrated sand. The decrease in reservoir porosity and permeability caused by sand settlement has a significant impact on production. The impact of sand production on reservoir fluid fluidity shows that fluid flow is inhibited near the wellbore, while fluid flow performance increases far away from the wellbore. The numerical model and analysis presented here could provide useful insight into changes in reservoir physical properties and production laws caused by sand production in the natural gas hydrate-bearing marine sediments using depressurization method.

\section{Introduction}

Natural gas hydrate (NGH) is an ice-like solid compound formed by natural gas (the main component methane) and water under high-pressure and low-temperature conditions [1]. Its large reserves and wide distribution are considered as one of the potential alternative energy sources [2]. Many countries with hydrate reservoirs have listed hydrate development as national plans [3-5].

The northern slope of the South China Sea is a hot area for research on gas hydrate exploration and test production in China [6]. The northern slope of the South China Sea has been explored by the China Geological Survey for rich natural gas hydrate resources $[7,8]$. In March 2020, the second round of natural gas hydrate test production in the South China Sea natural gas hydrate reservoir adopted horizontal well depressurization method for continuous production for 30 days, creating a world record for the test production of $2.87 \times 10^{4} \mathrm{~m}^{3} /$ day [9]. However, the natural gas hydrate reservoirs in the South China Sea are argillaceous silt reservoirs, which are characterized by the content of fine grain particles $(\leq 60 \mu \mathrm{m})$ in the sediments as high as $88 \%$ and gas hydrate as reservoir cement $[10,11]$. With the decomposition of hydrate in the reservoir, the large amount of sand migration has greatly increased the difficulty of sand control precision design and the problem of reservoir blockage $[12,13]$. There are engineering technical problems such as low productivity and easy sand production in reduced 
pressure mining. Therefore, it is urgent to carry out research on both gas and sand production law and change of reservoir physical properties to provide basic theoretical support for mine applications.

The research on sand production in hydrate reservoirs mainly focuses on the prevention of sand production wellbore and the study of overall sand migration in the hydrate reservoir. Experts and scholars have put forward many suggestions based on their own research results. Li et al. and Cao et al. believe that the secondary formation of hydrates and clay accumulation on the sand control medium are the key to clogging $[14,15]$. They suggested that a sand-control gravel sizing method called "Holding Coarse Expelling Fine Particles (HCEFP)" and artificial interference of downhole temperature was proposed to tackle the problems caused by possible screen clogging $[16,17]$. Uchida et al. establish thermohydromechanically coupled formulation to research the features of sand production in gas hydrate-bearing sediments. It is found that lowering depressurization rate was the most effective in reducing sand production for a given gas production [18]. Ning et al. proposed a thermohydromechanical-coupled natural gas hydrate reservoir bearing particles by coupling of the TOUGH+Hydrate, FLAC3D, and PFC3D. They proposed that how to carry out sand control design should be based on ensuring the gas production of hydrate reservoirs [19]. Yan et al. established a two-dimensional small-scale model by combining TOUGH+ABAQUS to analyze the sand production around the wellbore. They proposed that there is a certain relationship between the speed of natural gas hydrate decomposition and the amount of sand produced [20]. Yu et al. employed the CMG+STARS to qualitatively analyze the laws of sand production in gas production from hydrates. An improper sand control design criteria can induce substantial sand migration and led to clay logging in near well formations, restricting gas production capability [21]. Their research provides inspiration and guidance for subsequent simulation of sand production from natural gas hydrate reservoirs. However, the situation of hindering trial mining caused by sand production in different trial mining sites is different. Further research is needed for the impact of sand blockage on the gas production of unconsolidated natural gas hydrate reservoirs in the South China Sea. This research utilizes a multifield coupling model based on the South China Sea natural gas hydrate reservoir to systemically analyze both the quantitative prediction of gas and sand production and influence of sand process on reservoir physical properties and fluid flow performance.

\section{Simulation Preparation}

\subsection{Model Assumptions}

(1) Considering three phases: vapor-liquid-solid, and five components: natural gas hydrate, methane gas, water, solid sand, and migrating sand

(2) Sand has the same critical sand detachment speed in the natural gas hydrate layer
(3) Migrating sand flows with the fluid without changing the fluid properties

(4) Considering the influence of gravity and capillary force on gas and water seepage

(5) Solid sand does not occupy absolute porosity, while natural gas hydrates occupy absolute porosity

2.2. Sand Detachment. From the assumptions, it is known that the detachment of sand particles in the sediment depends on the flow rate of water. When the water velocity exceeds the critical sand detachment speed, the solid sand begins to move with the formation water to become mobilized sand.

General formula for sand detachment is expressed as

$$
\text { Solid Sand }_{S} \rightarrow \text { Migrated Sand }_{W}
$$

Concentration equation for sand detachment is expressed as [22]

$$
\frac{\partial c}{\partial t}=-c \sigma f\left(\frac{v}{v_{\text {critl }}}-1\right)
$$

where $c$ is solid sand concentration per unit volume, mole $/ \mathrm{m}^{3}$; $t$ is reaction time, $\mathrm{d} ; \sigma$ is solid sand detachment factor, $1 / \mathrm{d} ; f(\mathrm{x})$ is Heaviside step function; $v$ is flow rate of water, $\mathrm{m} / \mathrm{d} ; v_{\text {critl }}$ is critical sand detachment speed.

2.3. Sand Migration and Sedimentation. Ensure the rationality of sand migration in fluid through mass conservation equation. The solute transport mass conservation equation is expressed as [23]

$$
\frac{\partial}{\partial t}\left(\Phi_{f} c_{m}+c_{s}\right)+\nabla\left[-D \nabla c_{m}+v c_{m}\right]=0
$$

where $\Phi_{f}$ is effective porosity; $c_{m}$ and $c_{s}$ are migrated and settled sand concentrations, respectively, mole $/ \mathrm{m}^{3}$.

General formula for Sand sedimentation is expressed as

$$
\text { Migrated Sand }{ }_{W} \rightarrow \text { Settled sand }{ }_{S}
$$

Concentration equation for sand sedimentation is expressed as [21]

$$
\frac{\partial c_{s}}{\partial t}=\lambda c_{m} v
$$

where $\lambda$ is the filter coefficient.

2.4. Porosity-Permeability Equation. The permeability changes of natural gas hydrate reservoirs depend on effective porosity. It is calculated as the ratio of volume of water and gas to total matrix volume. With natural gas hydrate decomposition, the volume of solid hydrate gradually decreases. 
TABLE 1: Important model parameter.

\begin{tabular}{|c|c|c|c|}
\hline Parameter & Value & Parameter & Value \\
\hline Initial pressure $P_{0}$ & $10 \mathrm{MPa}$ & Initial temperature $T_{0}$ & $13^{\circ} \mathrm{C}$ \\
\hline $\begin{array}{l}\text { Initial natural gas hydrate saturation of natural } \\
\text { gas hydrate sediment } S_{H} \text { [26] }\end{array}$ & 0.3 & Initial permeability $K[27]$ & $3 \mathrm{mD}$ \\
\hline $\begin{array}{l}\text { Initial water saturation of natural gas hydrate } \\
\text { sediment } S_{W}\end{array}$ & 0.65 & Initial gas saturation of natural gas hydrate sediment $S_{G}$ & 0.05 \\
\hline Natural gas hydrate sediment thickness [28] & $30 \mathrm{~m}$ & Initial porosity of natural gas hydrate sediment $\varphi$ & 0.3 \\
\hline Depth & $1200 \mathrm{~m}$ & Bottom hole pressure & $3 \mathrm{MPa}$ \\
\hline Over layer thickness & $15 \mathrm{~m}$ & Under thickness & $15 \mathrm{~m}$ \\
\hline Initial porosity of over/under layer & 0 & Initial sand concentration of natural gas hydrate sediment & $921.74 \mathrm{~mole} / \mathrm{m} 3$ \\
\hline
\end{tabular}

Therefore, the effective porosity is also gradually increased, which is expressed as

$$
\begin{aligned}
\Phi_{f} & =\frac{V_{f}}{V_{B}}, \\
V_{B i} & =V_{m}+V_{f}+V_{H}, \\
V_{S} & =\frac{m_{S} \cdot \mathrm{CWM}}{\rho_{S}},
\end{aligned}
$$

where $V_{f}$ is volume of fluid, $\mathrm{m}^{3} ; V_{B}$ is initial bulk volume of a grid block, $\mathrm{m}^{3} ; V_{m}$ is volume of total matrix, $\mathrm{m}^{3} ; V_{H}$ is volume of natural gas hydrate, $\mathrm{m}^{3} ; V_{S}$ is volume of sand deposit, $\mathrm{m}^{3} ; m_{S}$ is initial sand concentration, mole $/ \mathrm{m}^{3}$; CWM is molecular mass of sand, $\mathrm{kg} /$ mole; $\rho_{S}$ is sand mass density, $\mathrm{kg} / \mathrm{m}^{3}$.

The relationship between effective porosity and permeability is represented by the following equation:

$$
K(\Phi)=K_{0} \cdot\left[\frac{\Phi_{f}}{\Phi_{0}}\right]^{\text {ckpower }} \cdot\left[\frac{\left(1-\Phi_{0}\right)}{\left(1-\Phi_{f}\right)}\right]^{2}
$$

where $K_{0}$ is initial natural gas hydrate reservoir permeability, $\mathrm{mD}$; ckpower is power-law constant, $3 ; \varphi_{0}$ is initial effective porosity.

\subsection{Natural Gas Hydrate Decomposition Equation. Accord-} ing to 1 standard volume of natural gas hydrate decomposition, 164 standard volumes of gas can be released [24]. The natural gas hydrate decomposition process can be simply expressed as the decomposition of natural gas hydrate into gaseous methane and liquid water. General formula for natural gas hydrate decomposition is expressed as

$$
\mathrm{CH}_{4} \cdot n \mathrm{H}_{2} \mathrm{O}(\mathrm{s}) \pm \mathrm{H} \Leftrightarrow \mathrm{CH}_{4}+n \mathrm{H}_{2} \mathrm{O}(w)
$$

where $n$ is natural gas hydrate dissociation factor, $5.75 ; H$ is natural gas hydrate dissociation enthalpy, J/mole;

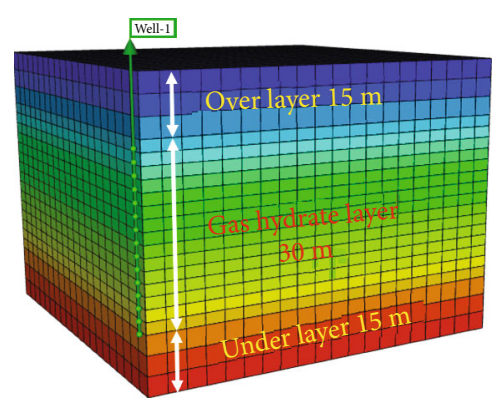

FIGURE 1: Schematic diagram of natural gas hydrate reservoir.

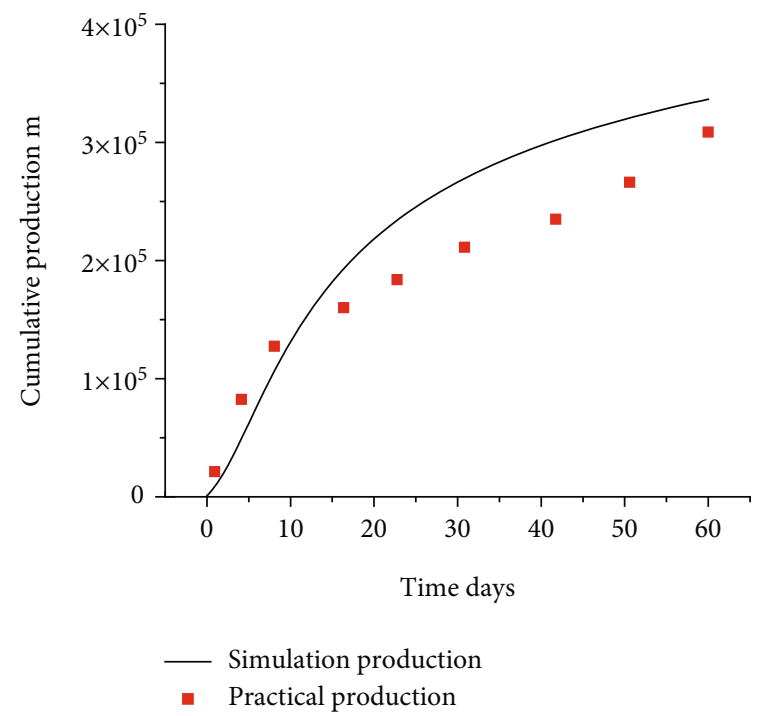

FIgURE 2: Simulation results of cumulative gas production compared with field measured date from Shenhu pilot test.

Natural gas hydrate decomposition equation is expressed as [25]

$$
n_{d}=k_{d}^{0} \exp \left(-\frac{E}{R T}\right) \Phi_{f}^{2} A_{\mathrm{HS}} S_{h} S_{w}\left(p_{e}-p_{g}\right),
$$

where $n_{d}$ is natural gas hydrate decomposition rate, $\mathrm{gmol} /\left(\mathrm{d} \cdot \mathrm{m}^{3}\right) ; k_{d}^{0}$ is natural gas hydrate decomposition 


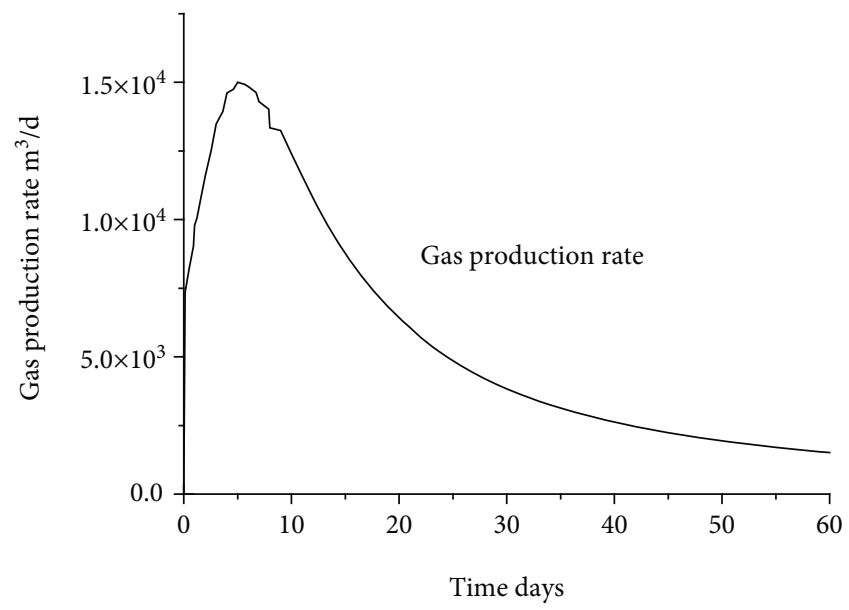

(a) Gas production rate

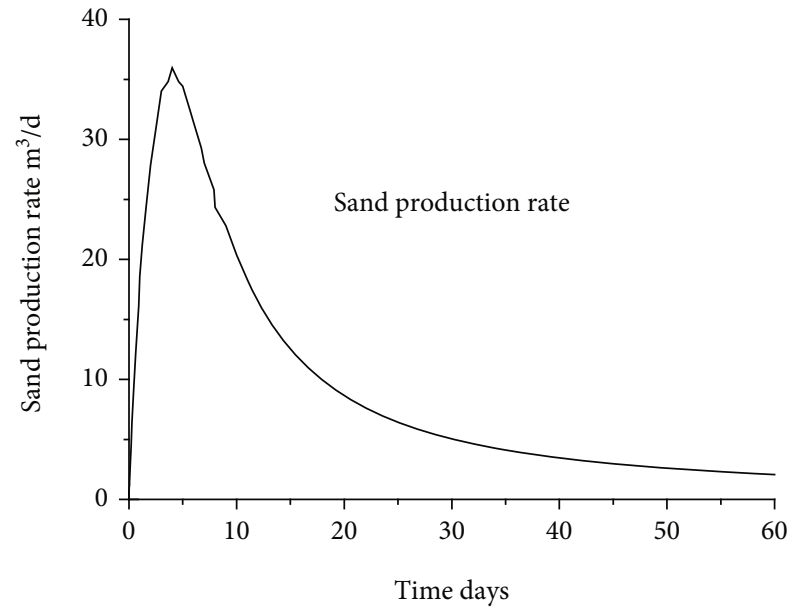

(b) Sand production rate

FIGURE 3: Simulation results of gas production rate and sand production rate.
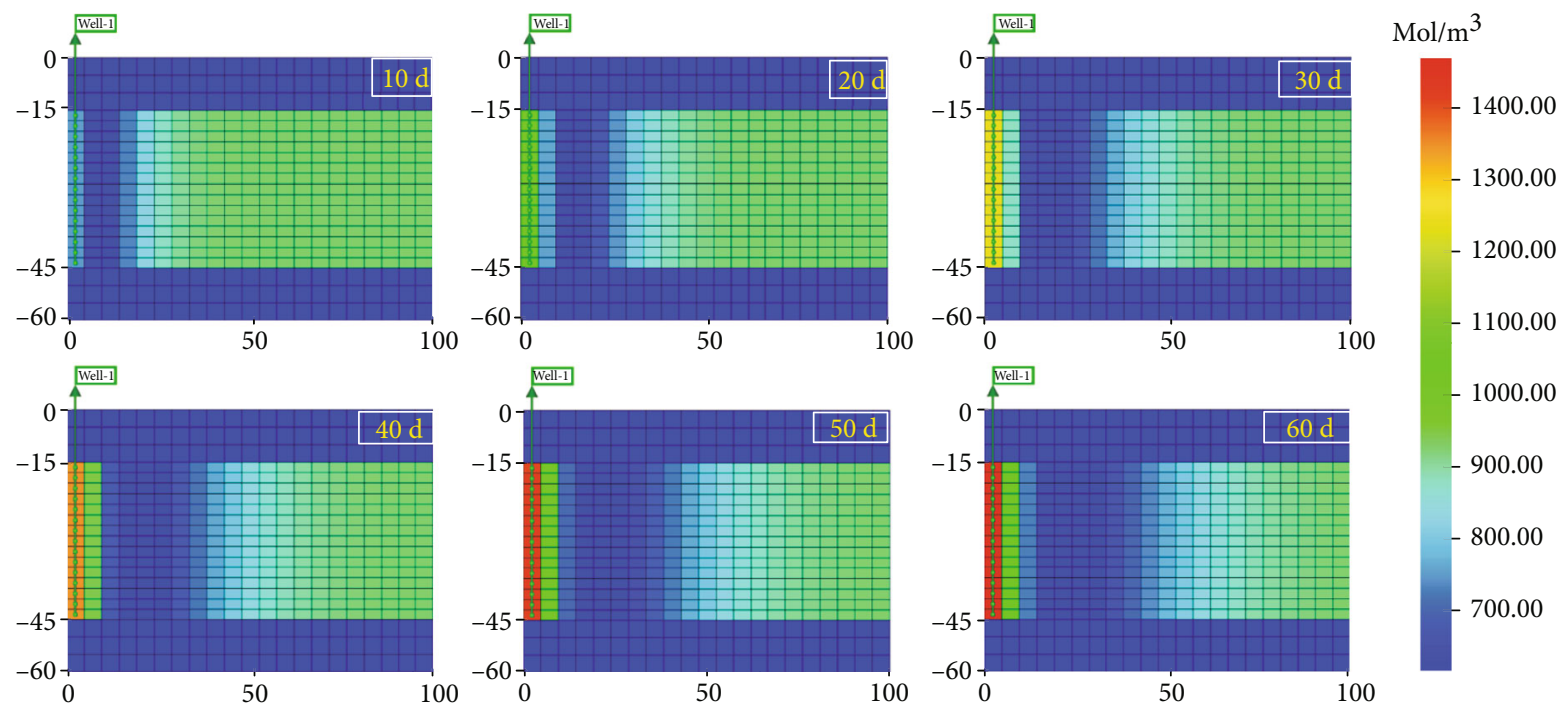

Figure 4: Evolution of spatial distribution of solid sand concentration.

frequency factor, mole $/\left(\mathrm{d} \cdot \mathrm{KPa} \cdot \mathrm{m}^{3}\right) ; E$ is reaction activation energy, $\mathrm{J} / \mathrm{mole} ; A_{\mathrm{HS}}$ is natural gas hydrate surface area, $\mathrm{m}^{2} / \mathrm{m}^{3} ; R$ is gas constant, $\mathrm{J} /($ mole. $\mathrm{K}) ; P_{e}$ and $p_{g}$ are natural gas hydrate equilibrium pressure and gaseous pressure, respectively, $\mathrm{kPa}$.

\section{Numerical Simulation}

3.1. Model and Parameters. A natural gas hydrate simulator software CMG+STARS was used to simulate sand-containing natural gas hydrate reservoirs, which can be adopted to modeling the processes of natural gas hydrate production, such as natural gas hydrate decomposition, sand detachment, sand migration, sand sedimentation, and mass and heat transfer under complex situation of multiple components.

In this study, the multiphase flow natural gas hydrate model is established using the geological parameters of the natural gas hydrate reservoir in the Shenhu area of the South China Sea. The critical parameters of the model are shown in Table 1. As shown in Figure 1, the model consists of three parts: the over layer, the natural gas hydrate layer, and the under layer. The thickness of the natural gas hydrate layer is $30 \mathrm{~m}$, and the grid step is $5 \mathrm{~m} \times 5 \mathrm{~m} \times 2 \mathrm{~m}$. Both thickness of the over and under layer is $15 \mathrm{~m}$, and the grid step is $5 \mathrm{~m} \times 5 \mathrm{~m} \times 5 \mathrm{~m}$. Depressurization production of vertical well is used to develop natural gas hydrate reservoirs, which lasted 60 days.

3.2. Model Verification. As a key parameter of the practical production data, cumulative gas production is an important basis for verifying the accuracy of the model. The simulated accumulative gas against measured data of the 2017 South China Sea production test are presented in Figure 2. As shown in Figure 2, the cumulative gas production of the 

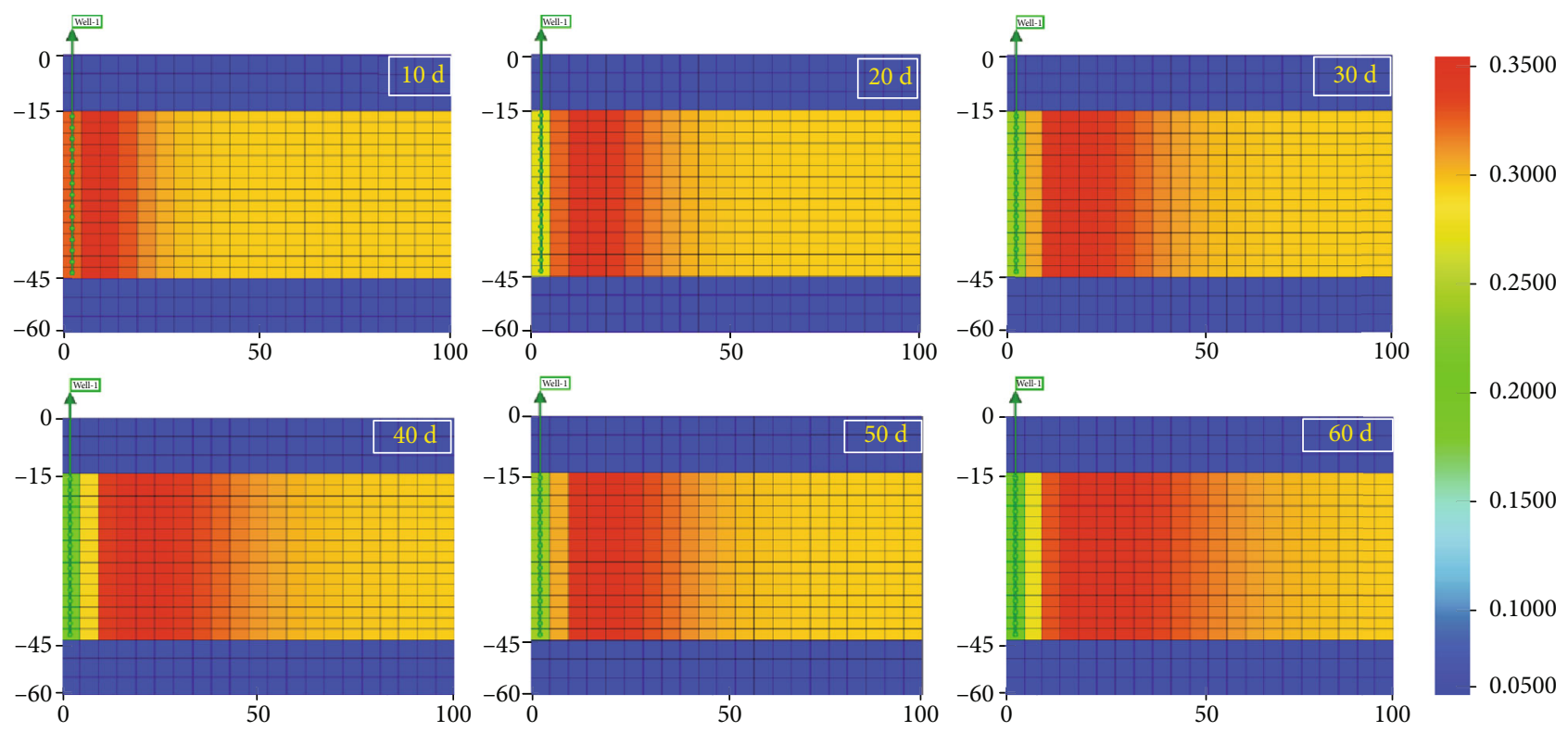

FIGURE 5: Evolution of spatial distribution of effective porosity.
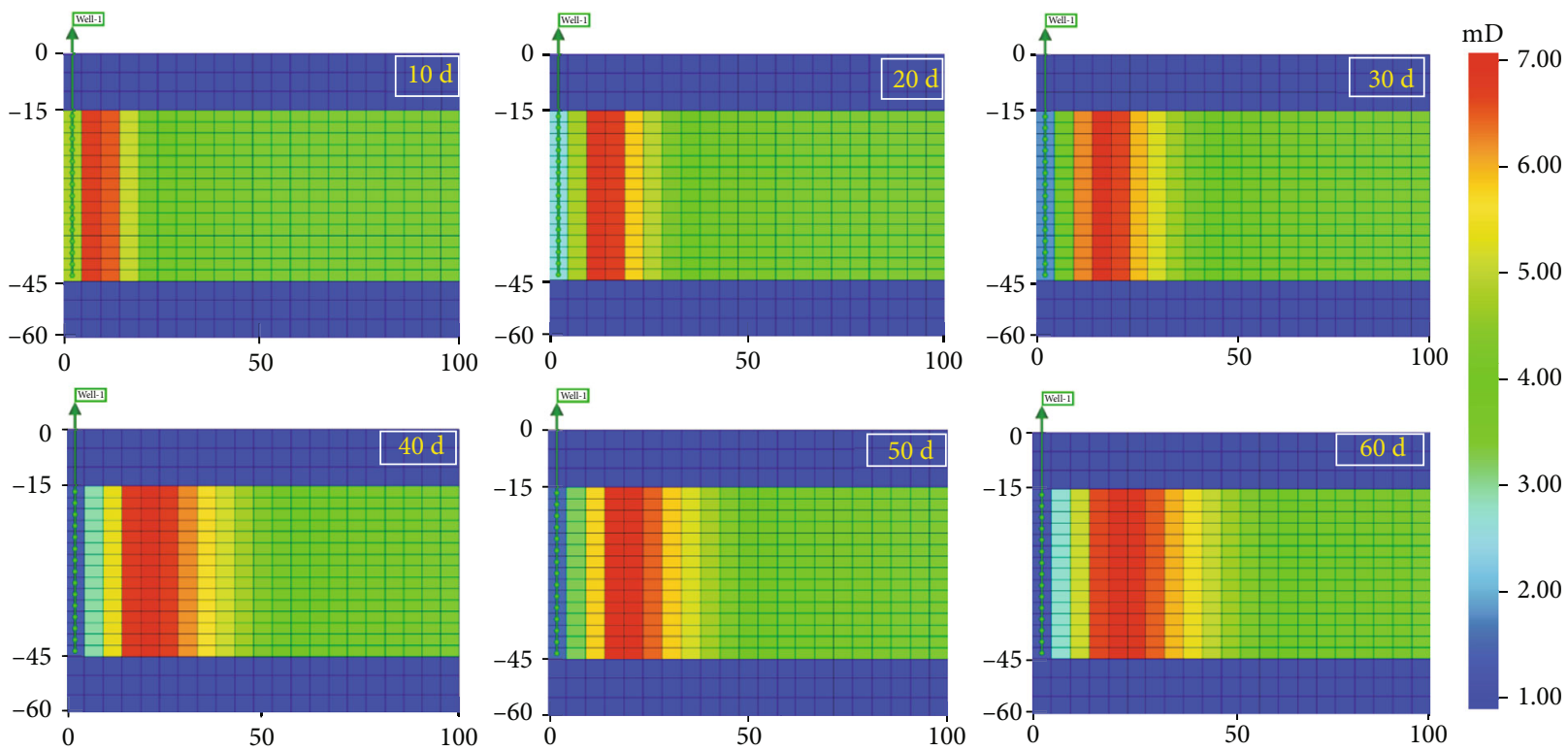

FIGURE 6: Evolution of spatial distribution of permeability.

model reaches $33.6 \times 10^{4} \mathrm{~m}^{3}$, which is basically consistent with the practical production data. The article model has a reasonable cumulative gas law.

\section{Result Analysis}

It can be seen in Figure 3(a) that the gas production rate rises rapidly in the early stage of production and, then, slowly decreases after reached the peak. In the $5^{\text {th }}$ of natural gas hydrate exploitation, the higher peak gas production rate value is $1.5 \times 10^{4} \mathrm{~m}^{3}$. Then, the gas production rate gradually decreases to $0.15 \times 10^{4} \mathrm{~m}^{3}$ at the $60^{\text {th }}$ of natural gas hydrate exploitation. The laws of sand production are similar to the gas production curve. Peak sand production rate appeared on the 4th day, which was $36 \mathrm{~m}^{3}$ (Figure 3(b)). It is worth noting that the sand production rate falls more quickly after reaching the peak value. Detailed analyses of the impact of sand production on natural gas hydrate exploitation will be made below.

The influence in the natural gas hydrate reservoir mining process caused by sand production is mainly concluded in three stages, namely, sand detachment, sand migration, and sand sedimentation. Figure 4 presents the evolution of distribution of sand concentration at the natural gas hydrate sediment as depressurization mining process. As shown by the figure, the high sand concentration region caused by sand 


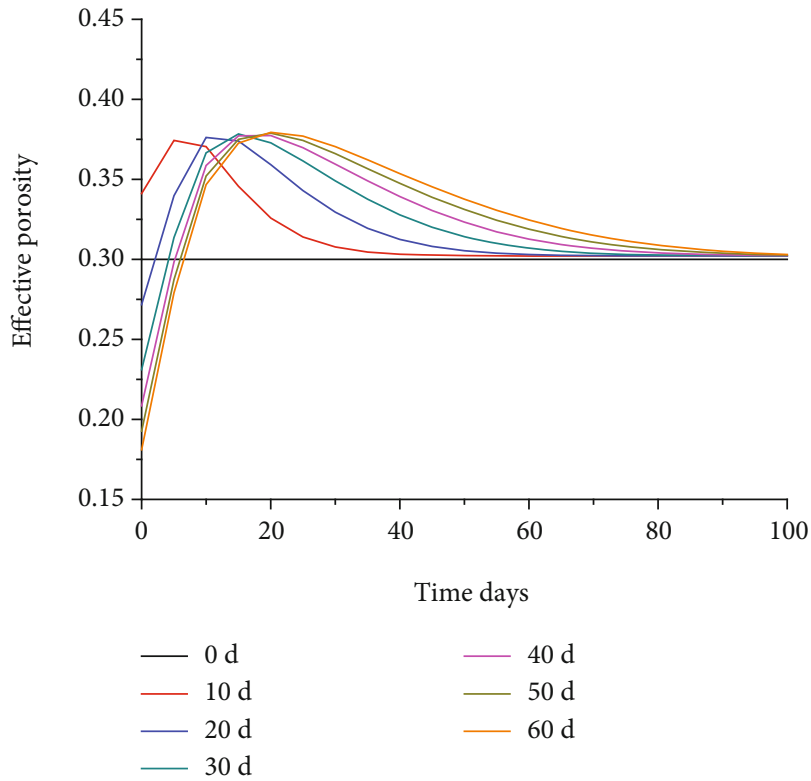

(a) Effective porosity

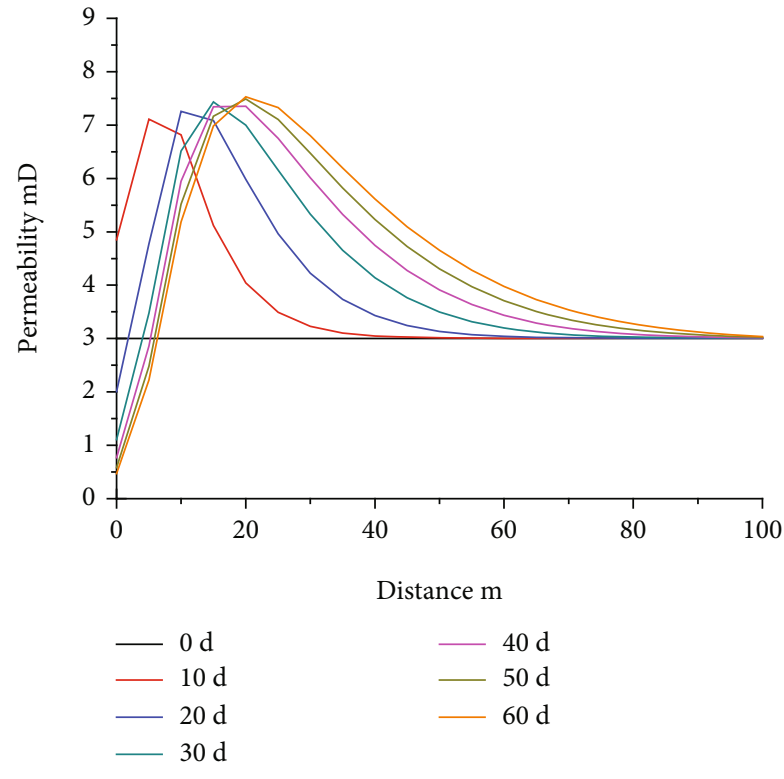

(b) Permeability

FIgURE 7: Variation of the sediment physical properties under different times.

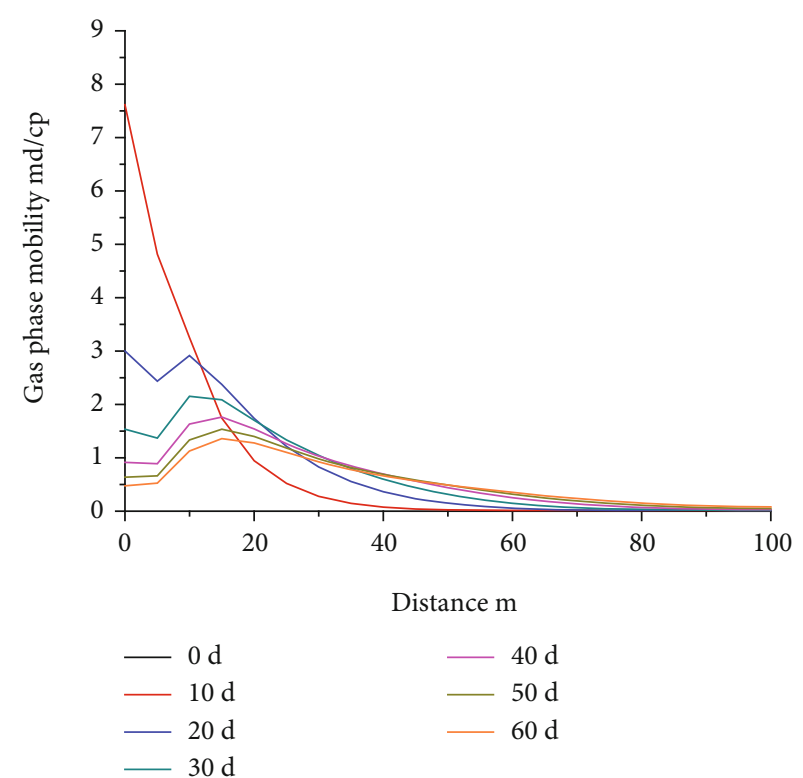

(a) Gas phase mobility

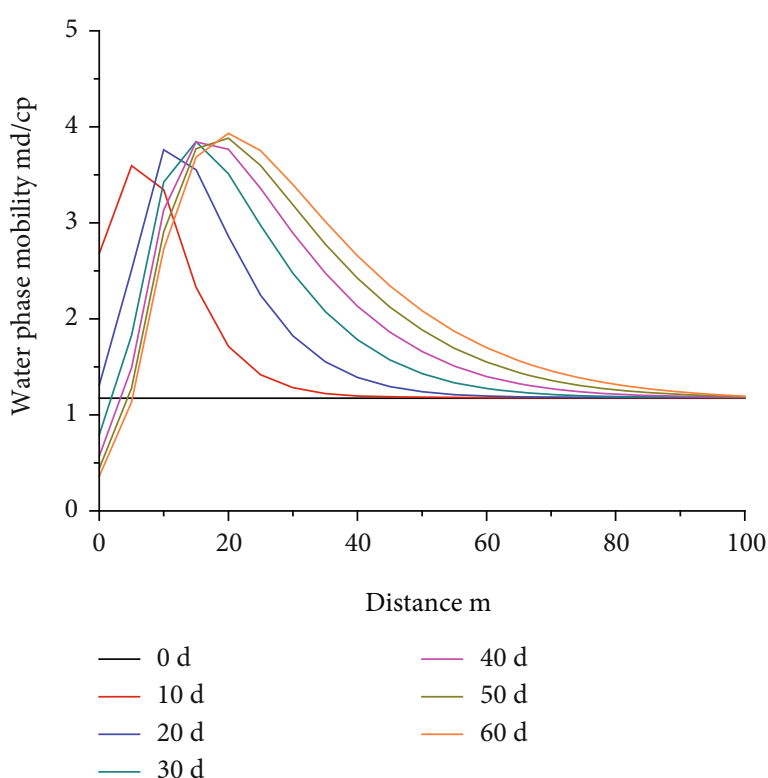

(b) Water phase mobility

FIgURE 8: Variation of the fluid mobility under different times.

sedimentation is mainly concentrated in the formation near the wellbore of the natural gas hydrate reservoir. The increase of sand concentration will affect the effective porosity to boost around the wellbore (Figure 5), and the development of the permeability during the depressurization-production process is shown in Figure 6. When the velocity of the pore water reaches the critical sand detachment speed, the formation sand is stripped and moved with the water. Sand migration accumulates near the wellbore and cannot be recovered in time. Then, the sand migration concentration reaches the settlement threshold and settlement occurs in the nearwellbore zone to block the pores. The maximum sand concentration reaches $1476.68 \mathrm{~mole} / \mathrm{m}^{3}$, which is 1.6 times the sand concentration of the original formation (Figure 5). As illustrated by Eq. (6), increased solid sand concentration leads to a decrease in effective porosity. Figure 7 (a) shows the chance of effective porosity with times. It can be concluded that the lower the effective porosity mainly concentrates on the closer the region to the wellbore. The minimum effective porosity reaches 0.18 around wellbore on the 
$60^{\text {th }}$ day, which is 0.6 times the initial effective porosity (Figure 7(a)). As mentioned above Eq. (9), the evolution of effective porosity will result to chance permeability of the natural gas hydrate sediment. Figure 7(b) shows the chance of permeability with times. Furthermore, the maximum effective porosity of the formation with only sand detachment and no sand subsidence reaches 0.38 at $20 \mathrm{~m}$ from the wellbore on the $60^{\text {th }}$ day (Figure $7(\mathrm{~b})$ ). As a result, the sand concentration near the wellbore will increase, resulting in a smaller effective porosity and permeability.

Figure 8 shows the gas phase and water phase mobility performance at different moments. As expected, the decrease of the effective porosity and permeability seriously affect the fluid mobility. As shown in Figures 8(a) and 8(b), conspicuous obstruction occurs near the wellbore after 20 days when the effective porosity and permeability are as low as 0.27 and $0.2 \mathrm{mD}$, respectively. This could explain why the gas and water production rates of this scheme continued to decline in the stages of the simulation.

\section{Conclusion}

This paper establishes a numerical simulation model based on the South China Sea first offshore NGH production data to simulate the impact of sand production on reservoir physical parameters and production during natural gas hydrate reservoir exploitation by depressurization. Based on the modeling results, the following conclusions can be obtained:

(1) In the process of gas hydrate depressurization production, when the reservoir sand meets the migration conditions, it migrates with the formation fluid to the wellbore. The concentration of migrating sand around the wellbore increases, resulting in sand settlement. Then, the porosity and permeability near the wellbore decrease, which in turn causes blockage of the formation, resulting in low production

(2) The simulation result shows that the evolution of spatial distribution of gas hydrate reservoir properties caused by sand settlement with time. The physical properties of the formation outside the range of sand settlement have no effect on the fluid and even increase the fluidity of the fluid. The range of formation blockage of natural gas hydrate reservoir at different times is considered for reservoir reformation, thus contributing to efficient and economical development

(3) Different types of natural gas hydrate reservoirs have different periods of formation blockage caused by sand settlement. The simulation results show that the reduced gas production rate is significantly affected by sand settlement near the wellbore about the 20th day of well start up, according to the South China Sea geological model. In view of the natural gas hydrate reservoirs in the South China Sea, stratigraphic reformation should be carried out around the 20th day after mining, so as to improve the formation seepage capacity

\section{Data Availability}

All results and data are in the manuscript.

\section{Conflicts of Interest}

The authors declared that there is no conflict of interest regarding the publication of this paper.

\section{Acknowledgments}

The project is supported by the National Natural Science Foundation of China (No.51974347, 51991364) and the Major Scientific and Technological Projects of CNPC under Grant ZD2019-184-002.

\section{References}

[1] Z. R. Chong, S. H. B. Yang, P. Babu, P. Linga, and X. S. Li, "Review of natural gas hydrates as an energy resource: prospects and challenges," Applied Energy, vol. 162, no. 1, pp. 1633-1652, 2016.

[2] Y. F. Makogon, "Natural gas hydrates-a promising source of energy," Journal of Natural Gas Science and Engineering, vol. 2, no. 1, pp. 49-59, 2010.

[3] R. Boswell, "Japan completes first offshore methane hydrate production test-methane successfully produced from deepwater hydrate layers," Center for Natural Gas and Oil, vol. 412, no. 1, pp. 386-7614, 2013.

[4] T. S. Collett, M. W. Lee, W. F. Agena et al., "Permafrost-associated natural gas hydrate occurrences on the Alaska North Slope," Marine and Petroleum Geology, vol. 28, no. 2, pp. 279-294, 2011

[5] K. Yamamoto and S. Dallimore, "Aurora-JOGMEC-NRCan Mallik 2006-2008 gas hydrate research project progress," Natural Gas \& Oil, vol. 304, no. 1, pp. 285-4541, 2008.

[6] N. Wu, G. Zhang, J. Liang et al., "Progress of gas hydrate research in northen South China Sea," Adwances in New and Renewable Energy, vol. 1, no. 1, pp. 80-94, 2013.

[7] J.-f. Li, J.-l. Ye, X.-w. Qin et al., "The first offshore natural gas hydrate production test in South China Sea," China Geology, vol. 1, no. 1, pp. 5-16, 2018.

[8] S. Wu, G. Zhang, Y. Huang, H. K. Wong, and J. Liang, "Gas hydrate occurrence on the continental slope of the northern South China Sea," Marine and Petroleum Geology, vol. 22, no. 3, pp. 403-412, 2005.

[9] J. L. Ye, X. W. Qin, W. W. Xie et al., "The second natural gas hydrate production test in the South China Sea," China Geology, vol. 3, no. 2, pp. 197-209, 2020.

[10] Y. Wan, N. Wu, G. Hu et al., "Reservoir stability in the process of natural gas hydrate production by depressurization in the Shenhu area of the South China Sea," Natural Gas Industry $B$, vol. 5, no. 6, pp. 631-643, 2018.

[11] J. He, Q. Y. Liang, Y. Ma, Y. H. Shi, and Z. Xia, "Geohazards types and their distribution characteristics in the natural gas hydrate area on the northern slope of the South China Sea," Geology in China, vol. 45, no. 1, pp. 15-28, 2018.

[12] H. Oyama, J. Nagao, K. Suzuki, and H. Narita, "Experimental analysis of sand production from methane hydrate bearing sediments applying depressurization method," Journal of MMIJ, vol. 126, no. 8/9, pp. 497-502, 2010. 
[13] Y. Li, L. Liu, C. Liu, J. Sun, Y. Ye, and Q. Chen, "Sanding prediction and sand-control technology in hydrate exploitation: a review and discussion," Marine Geology Frontiers, vol. 32, no. 7, pp. 36-43, 2016.

[14] S. C. Cao, J. Jang, J. Jung, W. F. Waite, T. S. Collett, and P. Kumar, "2D micromodel study of clogging behavior of fine-grained particles associated with gas hydrate production in NGHP-02 gas hydrate reservoir sediments," Marine and Petroleum Geology, vol. 108, no. 1, pp. 714-730, 2019.

[15] Y. Li, N. Wu, F. Ning et al., "Hydrate-induced clogging of sand-control screen and its implication on hydrate production operation," Energy, vol. 206, no. 1, article 118030, 2020.

[16] Y. Li, F. Ning, N. Wu et al., "Protocol for sand control screen design of production wells for clayey silt hydrate reservoirs: a case study," Energy Science \& Engineering, vol. 8, no. 5, 2020.

[17] Y. Li, G. Hu, C. Liu et al., "Gravel sizing method for sand control packing in hydrate production test wells," Petroleum Exploration and Development, vol. 44, no. 6, pp. 1016-1021, 2017.

[18] S. Uchida, A. Klar, and K. Yamamoto, "Sand production model in gas hydrate-bearing sediments," International Journal of Rock Mechanics and Mining Sciences, vol. 86, no. 1, pp. 303-316, 2016.

[19] F. L. Ning, J. X. Sun, Z. C. Liu, and J. Q. Liang, "Prediction of sand production in gas recovery from the Shenhu hydrate reservoir by depressurization," in Proceeding of 9th International Conference on Gas Hydrate, Denver, Colorado, USA, 2017.

[20] C. Yan, Y. Li, Y. Cheng et al., "Sand production evaluation during gas production from natural gas hydrates," Journal of Natural Gas Science and Engineering, vol. 57, no. 1, pp. 77-88, 2018.

[21] L. Yu, L. Zhang, R. Zhang, and S. Ren, "Assessment of natural gas production from hydrate-bearing sediments with unconsolidated argillaceous siltstones via a controlled sandout method," Energy, vol. 160, no. 1, pp. 654-667, 2018.

[22] C. M. Istchenko and I. D. Gates, "Well/wormhole model of cold heavy-oil production with sand," SPE Journal, vol. 19, no. 2, pp. 260-269, 2014.

[23] P. Bedrikovetsky, F. D. Siqueira, C. A. Furtado, and A. L. S. Souza, "Modified particle detachment model for colloidal transport in porous media," Transport in Porous Media, vol. 86, no. 2, pp. 353-383, 2011.

[24] F. Takeuchi, M. Hiratsuka, R. Ohmura, S. Alavi, A. K. Sum, and K. Yasuoka, "Water proton configurations in structures I, II, and H clathrate hydrate unit cells," The Journal of Chemical Physics, vol. 138, no. 12, article 124504, 2013.

[25] H. Kim, P. R. Bishnoi, R. A. Heidemann, and S. S. H. Rizvi, "Kinetics of methane hydrate decomposition," Chemical Engineering Science, vol. 42, no. 7, pp. 1645-1653, 1987.

[26] L. Gang, L. Xiaosen, C. Qi, and C. Zhaoyang, "Numerical simulation of gas production from gas hydrate zone in Shenhu Area, South China Sea," Acta Chimica Sinica, vol. 68, no. 11, pp. 1083-1092, 2010.

[27] X. Qin, Q. Liang, J. Ye et al., "The response of temperature and pressure of hydrate reservoirs in the first gas hydrate production test in South China Sea," Applied Energy, vol. 278, no. 1, article 115649, 2020.

[28] J.-C. Feng, Y. Wang, X.-S. Li, G. Li, Y. Zhang, and Z. Y. Chen, "Production performance of gas hydrate accumulation at the GMGS2-Site 16 of the Pearl River Mouth Basin in the South China Sea," Journal of Natural Gas Science and Engineering, vol. 27, no. 1, pp. 306-320, 2015. 